\section{SYNTHESIS OF GRAPHENE ON Ni/SiC STRUCTURE}

\author{
Petr Machac - Tomas Hrebicek
}

\begin{abstract}
- graphene is a promising material with excellent electrical, thermal, optical and mechanical properties. Therefore, it is a material of high relevance for various applications in many branches of technique. Graphene has received much attention recently in scientific community. The contribution reports formation and characterization of few-layer graphene (FLG) films on a $\mathrm{SiC}$ substrate from nickel silicide supersaturated with carbon by annealing at a favourable low temperature.
\end{abstract}

Keywords: graphene, $\mathrm{Ni} / \mathrm{SiC}$ structure, carbon segregation, Raman spectroscopy

\section{INTRODUCTION}

Graphene, a mono-layer or few-layer of $\mathrm{sp}^{2}$ hybridized carbon atoms, has significant perspective of use in microelectronics, due to its highly interesting features [1] - high carrier mobility, excellent electrical conductivity and superior thermal conductivity. These favourable properties predestinate graphene as a possible candidate for post-silicon electronics.

Currently, graphene can be prepared by different methods such as mechanical cleavage or exfoliation [2], chemical reduction of graphite oxide [3], epitaxial growth by $\mathrm{SiC}$ thermal graphitization in vacuum [4] or in an $\mathrm{Ar}$ atmosphere [5] and chemical vapour deposition (CVD) on transition metals [6]. Very promising is the synthesis of graphene on $\mathrm{SiC}$ substrates at a relatively low temperature [7] based on the carbon segregation from a metal layer saturated by carbon. This technique utilizes a $\mathrm{Ni} / \mathrm{SiC}$ structure. The method is very promising for stripping of graphene layers from the substrate and their transfer to other substrates. Annealing of the structure results in a chemical reaction that forming silicides and carbon rich products at the $\mathrm{Ni}-\mathrm{SiC}$ interface and in accumulation of graphite at the top of the Ni layer.

\section{SAMPLE PREPARATION}

N-type $4 \mathrm{H}-\mathrm{SiC}$ substrate wafers, $4^{\circ}$ off-axis, Si-face polished, doping level $4 \times 10^{18} \mathrm{~cm}^{-3}$ (supplied by SiCrystal A.G.) were used in our experiments. Deposition of $\mathrm{Ni}$ metallization was performed using an e-beam evaporator at $135^{\circ} \mathrm{C}$ in vacuum of $2 \times 10^{-4} \mathrm{~Pa}$. The purity of $\mathrm{Ni}$ was $4 \mathrm{~N}$ or $5 \mathrm{~N}$. Alternatively the metallization was prepared by magnetron sputtering in an Ar atmosphere (the purity of the deposition target was $4 \mathrm{~N}$ ). Standard thickness of $\mathrm{Ni}$ layer was $300 \mathrm{~nm}$. Immediately before metal deposition, $\mathrm{SiC}$ wafers were chemically cleaned using the previously mentioned process [8].

Graphene layers were prepared by thermal treatment of $\mathrm{Ni} / \mathrm{SiC}$ structures in a small vacuum chamber equipped with a resistively heated table (temperature ranging from 850 to $1050{ }^{\circ} \mathrm{C}$, the annealing duration ranging from 0 to $120 \mathrm{~s})$. First of all, the $\mathrm{Ni} / \mathrm{SiC}$ samples were degassed at $350^{\circ} \mathrm{C}$ for $5 \mathrm{~min}$ and then annealed at a pressure bellow $3 \times 10^{-4} \mathrm{~Pa}$. Temperature was measured with an optical pyrometer. The heating rate was approximately $17.5^{\circ} \mathrm{C} / \mathrm{s}$ and the cooling rate was $15^{\circ} \mathrm{C} / \mathrm{s}$.

The samples were analysed by means of Raman spectroscopy using a LabRaman apparatus, Dilor system, with a $532.2 \mathrm{~nm}$ laser and spot diameter $1 \mu \mathrm{m}$. XPS measurements were performed in ultra high vacuum $\left(10^{-8} \mathrm{~Pa}\right)$ using an ESCAProbe $\mathrm{P}$ apparatus (Omicron Nanotechnology Ltd.) equipped with an $\mathrm{Al}$ anode as an X-ray source with energy $1486.7 \mathrm{eV}$. The X-ray source was monochromatic. The size of the analysed area was approximately $1 \mathrm{~mm}^{2}$. Ar ions of $5 \mathrm{keV}$ energy were used for ion sputtering during depth profiling. AFM analysis was conducted in a Veeco CP II apparatus in the tapping mode.

\section{RESULTS}

In Fig. 1, an example of Raman spectra of the structure after annealing at $950{ }^{\circ} \mathrm{C}$ (annealing period $30 \mathrm{~s}, \mathrm{Ni}$ was deposited by the sputtering) is shown. The solid line represents the spectrum after annealing, the dashed line represents the spectrum of the graphene layer exfoliated onto a $\mathrm{SiO}_{2} / \mathrm{Si}$ substrate. Exfoliation was done by etching the silicide layer by a mixture of $\mathrm{HF}$ and $\mathrm{HNO} 3$ acids with the help of polymethyl methalcrylate (PMMA). PMMA was burned after transferring onto $\mathrm{SiO}_{2}$ in $\mathrm{H}_{2}$ atmosphere at $400{ }^{\circ} \mathrm{C}$. The integrated intensity ratio $I_{\mathrm{D}} / I_{\mathrm{G}}$ for the $\mathrm{D}$ and $\mathrm{G}$ bands is widely used for the defect quantity characterizing in graphitic materials [9], the main parameter is the crystallite size $L_{\mathrm{a}}$

$$
L_{a}(n m)=\frac{560}{E_{\text {laser }}^{4}(\mathrm{eV})}\left(\frac{I_{\mathrm{D}}}{I_{\mathrm{G}}}\right)^{-1},
$$

where $E_{\text {laser }}$ is the laser excitation energy utilized in Raman analysis. Similarly, the integrated intensity ratio

* University of Chemistry and Technology, Prague, Technicka 5, 16628 Prague 6, Czech Republic; petr.machac@vscht.cz 


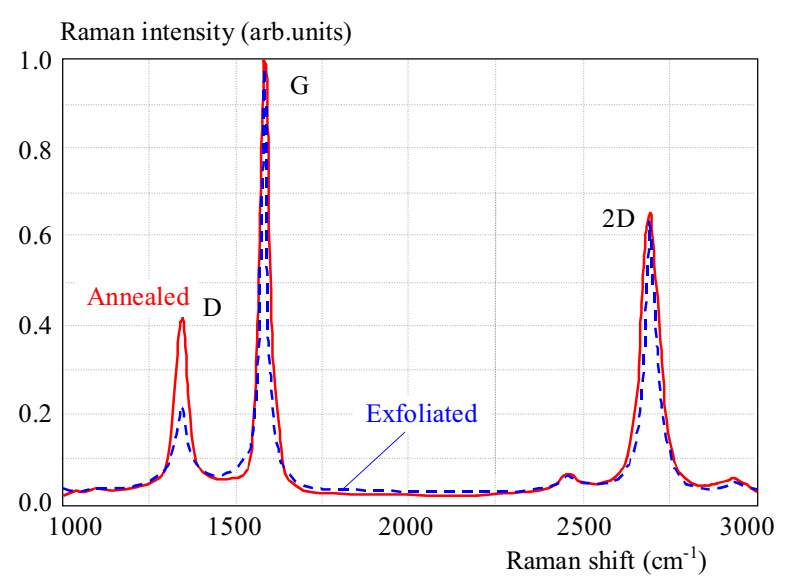

Fig. 1. Raman spectra of $\mathrm{Ni} / \mathrm{SiC}$ sample after the annealing and after the exfoliation

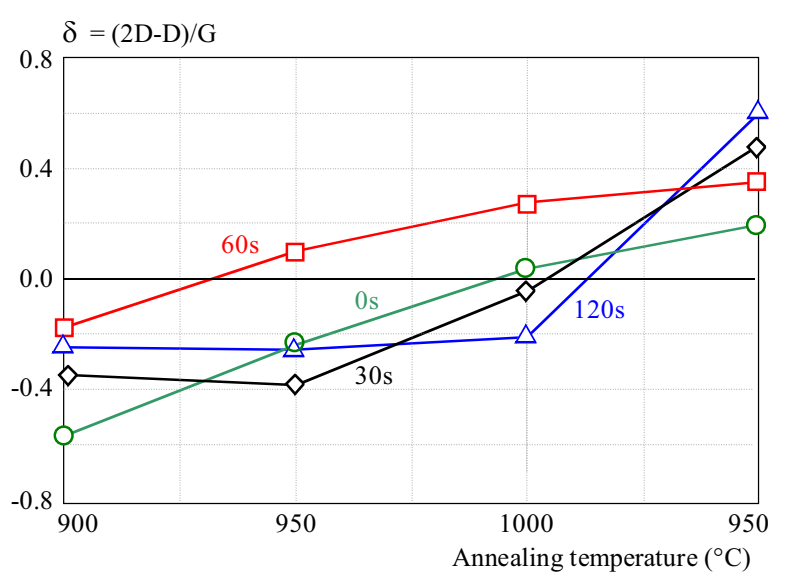

Fig. 2. Parameter $\delta$ as a function of the annealing temperature and time for Ni metallization with $5 \mathrm{~N}$ purity

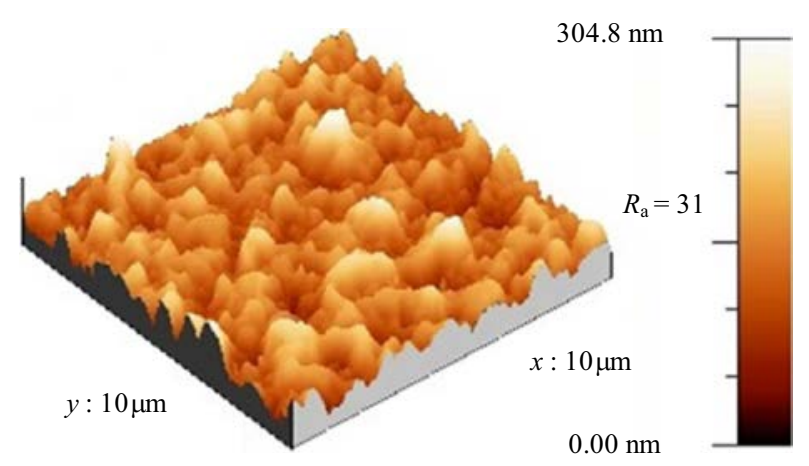

Fig. 3. AFM picture of the graphene film surface prepared on the $\mathrm{Ni}(300) / \mathrm{SiC}$ structure annealed at $1000^{\circ} \mathrm{C}$ for $120 \mathrm{~s}$

$I_{2 \mathrm{D}} / I_{\mathrm{G}}$ for the $2 \mathrm{D}$ and $\mathrm{G}$ bands is used for determination of the number of carbon layer [10]. It is possible to estimate that graphene in Fig. 1 contains 4 carbon layers, its crystallite size is $43 \mathrm{~nm}$ and exfoliation increases its value to $82 \mathrm{~nm}$. The difference is probably due to a smoother surface of $\mathrm{SiO}_{2}$.

Graphene preparation was aimed at studying the influence of $\mathrm{Ni}$ deposition conditions, annealing temperature and annealing time on graphene parameters. The quality of the graphene layer increases with the increasing
$I_{2 \mathrm{D}} / I_{\mathrm{G}}$ ratio in the Raman spectrum (the number of carbon monolayers in graphene decreases) and at the same time with the decreasing $I_{\mathrm{D}} / I_{\mathrm{G}}$ ratio (the crystallite size La increases). This motivated us to introduce a criterion for evaluation of graphene layers quality in the form of the parameter [8]

$$
\delta=\left(I_{2 \mathrm{D}}-I_{\mathrm{D}}\right) / I_{\mathrm{G}}
$$

which should be as high as possible.

Some results are presented in Fig. 2, where Ni with purity $5 \mathrm{~N}$ was deposited by evaporation. The figure shows the dependence of $\delta$ on the annealing time and temperature. Parameter $\delta$ increases with increasing temperature for all annealing periods and reaches a maximal value 0.6 for $1050^{\circ} \mathrm{C}$ and $120 \mathrm{~s}$. Metallizations prepared by sputtering and by evaporation with less pure nickel show similar behaviours. The results of optimization are summarized in Tab. 1. The table shows the values of $\delta, 2 \mathrm{D} / \mathrm{G}$ and $\mathrm{D} / \mathrm{G}$ ratios, and $L_{\mathrm{a}}$ for graphene prepared from all metallizations at the annealing temperature $1050^{\circ} \mathrm{C}$. The data are the average values of all annealing periods. In the case of nickel with purity $5 \mathrm{~N}$ we obtained a graphene film with the highest value of $\delta=0.42$. The prepared graphene has a nature of three-layer graphene but its crystallinity is low. The first two metallizations produce four-layer graphene with a better crystallite structure.

For verification of the results provided by Raman spectroscopy, the $\mathrm{Ni} / \mathrm{SiC}$ structure annealed at $1000{ }^{\circ} \mathrm{C}$ for $120 \mathrm{~s}$ (evaporation, $\mathrm{Ni}$ of $4 \mathrm{~N}$ purity) was subjected to XPS analysis (spectrum not shown here). Carbon is a dominant element on the structure surface. The dominant C1s peak at $284.5 \mathrm{eV}$ corresponds to the C-C bond [11] and confirms the presence of graphene.

The morphology of the structure surfaces was studied by AFM. Figure 3 shows the surface morphology of the $\mathrm{Ni}(300) / \mathrm{SiC}$ structure (evaporation, $\mathrm{Ni}$ of $4 \mathrm{~N}$ purity) annealed at $1000{ }^{\circ} \mathrm{C}$ for $120 \mathrm{~s}$. Extensive reaction of the nickel film with the $\mathrm{SiC}$ substrate occurred during the annealing process. The reaction was not homogeneous, which is confirmed by large roughness $R_{\mathrm{a}}=31 \mathrm{~nm}$. The prepared graphene film lies on the metallization surface and consequently it exhibits a large number of defects, thus it has low crystallinity.

Finally the basic electronic parameters of prepared graphene were measured. Experiments were done with the metallization prepared by evaporation of $5 \mathrm{~N}$ nickel. For the measurements it is necessary to have a dielectric substrate, therefore a semiinsulating $\mathrm{SiC}$ plate (SI-SiC) was used and the graphene film on the interface between $\mathrm{SiC}$ and the metallization were tested (after annealing the silicide layer was etched-off by $\mathrm{HNO}_{3}$ acid hereby obtaining the graphene/SI-SiC structure). $\mathrm{Au}(30) / \mathrm{Cr}(10)$ contacts prepared by evaporation were applied to measure the electrical parameters by van der Pauw method. The obtained results are shown in Tab. $2\left(p_{\mathrm{s}}\right.$ is surface resistivity, $\mu_{\mathrm{H}}$ is Hall mobility and $c_{\mathrm{s}}$ is the concentration of charge carriers). Hall mobility of the prepared graphene 
Table 1. Results of the graphene film optimization

\begin{tabular}{ccccc}
\hline Deposition & $\delta$ & $2 \mathrm{D} / \mathrm{G}$ & $\mathrm{D} / \mathrm{G}$ & $L_{\mathrm{a}}(\mathrm{nm})$ \\
\hline Sputtering, $\mathrm{Ni}-4 \mathrm{~N}$ & $0.39 \pm 0.075$ & $0.58 \pm 0.05$ & $0.185 \pm 0.10$ & 97 \\
Evaporation, $\mathrm{Ni}-4 \mathrm{~N}$ & $0.39 \pm 0.05$ & $0.59 \pm 0.05$ & $0.20 \pm 0.08$ & 90 \\
Evaporation, $\mathrm{Ni}-5 \mathrm{~N}$ & $0.42 \pm 0.15$ & $0.86 \pm 0.07$ & $0.44 \pm 0.21$ & 41 \\
\hline
\end{tabular}

Table 2. Electrical parameters of graphene on SI SiC

\begin{tabular}{|c|c|c|c|c|}
\hline \multicolumn{2}{|c|}{ Annealing conditions } & \multirow{2}{*}{$\rho_{\mathrm{s}}(\Omega)$} & \multirow{2}{*}{$\mu_{\mathrm{H}}\left(\mathrm{cm}^{2} / \mathrm{Vs}\right)$} & \multirow{2}{*}{$c_{\mathrm{s}}\left(\mathrm{m}^{-2}\right)$} \\
\hline$T\left({ }^{\circ} \mathrm{C}\right)$ & $t(\mathrm{~s})$ & & & \\
\hline 1000 & 120 & $1130 \pm 24$ & $7.6 \pm 5.5 \times 10^{-2}$ & $7.21 \times 10^{18} \pm 5.2 \times 10^{16}$ \\
\hline 1050 & 60 & $527 \pm 2.5$ & $300 \pm 7.3$ & $3.85 \times 10^{17} \pm 7.3 \times 10^{15}$ \\
\hline
\end{tabular}

films is very low probably due to a large concentration of defects in graphene layers.

\section{CONCLUSIONS}

Graphene films were prepared by synthesis on a $\mathrm{SiC}$ substrate via Ni-silicidation reaction. Through optimization of the technological process, three-layer graphene was prepared. The best results were provided by evaporation of nickel with $5 \mathrm{~N}$ purity, the optimal annealing temperature was $1050{ }^{\circ} \mathrm{C}$ and the best annealing time was $120 \mathrm{~s}$. The graphene film was successfully exfoliated onto the $\mathrm{SiO}_{2} / \mathrm{Si}$ substrate and its crystallinity was better (the $I_{\mathrm{D}} / I_{\mathrm{G}}$ ratio is much smaller). XPS analysis confirmed the presence of graphene on the $\mathrm{Ni} / \mathrm{SiC}$ surface. Basic electrical parameters were measured, from the results it is evident that the graphene films have relatively low quality. The AFM measurement showed that the surface of metallizations is very rough. This fact confirms the poor quality of graphene. The next aim of our research will be concentrated on the preparation of graphene films with lower defectivity.

\section{Acknowledgments}

This study was supported by the Ministry of Health of the Czech Republic (projects 15-33018A and 15-33459A).

\section{REFERENCES}

[1] CHOI, W.-LAHIRI, I.-SEELABOYINA, R.-KANG, Y. S. : Synthesis of Graphene and its Applications: a Review, Cri. Rev. Solid State Mater. Sci. 35 No. 01 (2010), 52-71.

[2] NOvoselov, K. S.-GEIM, A. K.-MOROzOV, S. V.JIANG, D.-ZHANG, Y.-DUBONOS, S. V.-GRIGORIEVA, I. V.-FIRSOV, A. A. : Electric Field Effect in Atomically Thin Carbon Films, Science 306 No. 5696 (2004), 666-669.

[3] SCHEDIN, F.-GEIM, A. K.-MOROZOV, S. V.-HILL, E. W.-BLAKE, P.-KATSNELSON, M. I.-NOVOSELOV, K. S. : Detection of Individual Gas Molecules Adsorbed on Graphene, Natur. Mater. 6 No. 9 (2007), 65275-655.

[4] TANAKA, S.-MORITA, K.-HIBINO, H. : Anisotropic Layerby-Layer Growth of Grapheneon Vicinal $\mathrm{SiC}(0001)$ Surfaces, Phys. Rev. B 81 No. 04 (2010), 041406.
[5] OSTlER, M.-SPECK, F.-GICK, M.-SEYLlER, T.: Automated Preparation of High-Quality Epitaxial Graphene on 6H-SiC(0001), Phys. Status Solidi B 247 No. 11-12 (2010), 2924-2926.

[6] JUANG, Z. Y.-WU, C. Y.-LU, A. Y.-SU, C. Y.-LEOU, K. C.-CHEN, F. R.-TSAI, C. H. : Graphene Synthesis by Chemical Vapour Deposition and Transfer by a Roll-to-Roll Process, Carbon 48 No. 11 (2010), 3169-3174.

[7] JUANG, Z. Y.-WU, C. Y.-LO, C. W.-CHEN, W. Y.JUANY, C. F.-HWANG, J. C.-CHEN, F. R.-LEOU, K. C.-TSAI, C. H.: Synthesis of Graphene on Silicon Carbide Substrates at Low Temperature, Carbon 47 No. 08 (2009), 2026-2031.

[8] MACHAC, P.-FIDLER, T.-CICHON, S.-JURKA, V.: Synthesis of Graphene on Co/SiC Structure, J. Mater. Sci.: Mater. Electron. 24 No. 10 (2013), 3793-3799.

[9] CANADO, L. G.-TAKAI, K.-ENOKI, T.-ENDO, M.KIM, Y. A.-MIZUSAKI, H.-JORIO, A.-COELHO, L. N.MAGALHAES-PANIAGO, R.-PIMENTA, M. A.: General Equation for the Determination of the Crystallite Size La of Nanographite by Raman Spectroscopy, Applied Phys. Lett. 88 No. 03 (2006), 163106.

10] HAO, Y.-WANG, Y.-WANG, L.-NI, Z.-WANG, R.KOO, C. K.-SHEN, Z.-THONG, J. T. L.: Probing Layer Number and Stacking Order of Few-Layer Graphene by Raman Spectroscopy, Small 6 No. 02 (2010), 195-200.

[11] WOLAN, J. T.-GRAYSON, B. A.-KOHLSCHEEN, J.EMIROV, Y.-SCHLAF, R.-SWARTZ, W.-SADDOW, S. E.: Effect of Hydrogen Etching and Subsequent Sacrificial Thermal Oxidation on Morphology and Composition of $4 \mathrm{H}-\mathrm{SiC}$ Surfaces, J. Electronic Mat. 31 No. 05 (2002), 380-385.

Received 10 December 2015

Petr Machac was born in Hranice, Czech Republic, 1953. In 1977 he graduated in electrical engineering from the Czech Technical University Prague and received the PhD degree in electronics at the same university in 1982. From 1978 to 1984 he was with the Czech Technical University Prague. In 1991 he was appointed Associate Professor in electronics with the Czech Technical University Prague, being active with the University of Chemistry and Technology, Prague, from 1984 till now. His current research interest is in deposition of materials, formation of contacts on semiconductor materials (mainly $\mathrm{SiC}$ ), and preparation of graphene layers by several methods. $\mathrm{He}$ is the author or co-author of more than 60 articles in scientific journals and 100 contributions at international conferences. 